\title{
Saturated fat
}

National Diabetes Information Clearinghouse (NDIC)

\section{Definitions}

Fat

Defined by National Diabetes Information Clearinghouse (NDIC)

\section{Source}

National Diabetes Information Clearinghouse (U.S.). (2009). The diabetes dictionary. [Bethesda, Md.]: U.S. Dept. of Health and Human Services, National Institutes of Health, National Institute of Diabetes and Digestive and Kidney Diseases, National Diabetes Information Clearinghouse.

A type of dietary fat that can increase the risk of heart disease. Saturated fat is found in meat, poultry skin, butter, lard, shortening, and all milk and dairy products except fat-free versions. 